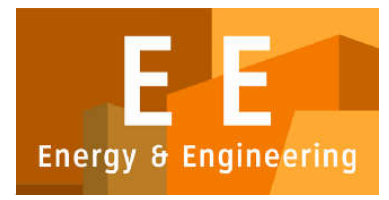

PAPER - OPEN ACCESS

\title{
Pengurangan Efek Bullwhip Pada Vendor Tunggal Dan Eceran Multi Di PT. XYZ
}

\author{
Author $\quad$ : Meilita Tryana Sembiring dan Feby Sanna Sibarani \\ DOI $\quad: 10.32734 /$ ee.v2i4.671 \\ Electronic ISSN $\quad: 2654-704 \mathrm{X}$ \\ Print ISSN : :2654-704X
}

Volume 2 Issue 4 - 2019 TALENTA Conference Series: Energy \& Engineering (EE)

This work is licensed under a Creative Commons Attribution-NoDerivatives 4.0 International License.

Published under licence by TALENTA Publisher, Universitas Sumatera Utara

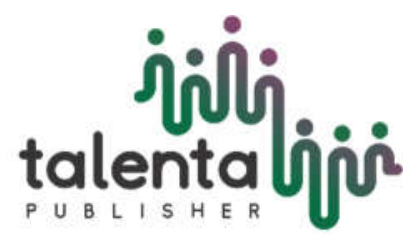




\section{jiditi (and \\ TALENTA Conference Series}

Available online at https://talentaconfseries.usu.ac.id

\title{
Pengurangan Efek Bullwhip Pada Vendor Tunggal dan Eceran Multi Di PT. XYZ
}

\author{
(Reduction of Bullwhip Effect in Single Vendor and Multi Retailer in PT. XYZ) \\ Meilita Tryana Sembiring ${ }^{\mathrm{a}}$, Feby Sanna Sibarani ${ }^{\mathrm{b}}$ \\ ${ }^{a}$ Dosen Departemen Teknik Industri USU, Jl. Almamater, Padang Bulan, Medan, Sumatera Utara 20155 \\ ${ }^{b}$ Mahasiswa Departemen Teknik Industri USU, Jl. Almamater, Padang Bulan, Medan, Sumatera Utara 20155
}

meilita_tryana@yahoo.com, febysannasibarani@gmail.com

\begin{abstract}
Abstrak
PT. XYZ merupakan perusahaan yang bergerak dalam produksi produk - produk olahan teh. Perusahaan telah memproduksi berbagai varian the yakni bentuk mau pun jenis teh. Objek penelitian ini ialah the dalam kemasan botol kaca dengan ukuran 220 ml. Ukuran the tersebut dipilih berdasarkan akumulasi dari penjualan the tertinggi. Terdapat perbedaan pada prediksi jumlah produksi yang akan dilakukan. Prediksi jumlah produksi dapat dilakukan dengan melakukan peramalan permintaan serta penggunaan metode yang tepat. Rantai pasok yang diteliti pada PT. XYZ terdiri atas Manufaktur (Vendor), Kantor Penjualan, dan Dister. Awalnya peramalan dilakukan pada masing - masing level rantai pasok dengan metode peramalan yang berbeda beda. Maka, diperlukan penyeragaman metode peramalan pada masing - masing pelaku rantai pasok. Berdasarkan pengujian metode peramalan yang dilakukan yakni metode Linear, Exponential Smoothing, Moving Average, dan Winter'sMethod. Diperoleh bahwa error terkecil terdapat pada metode peramalan Winter's Method dengan parameter Level sebesar 0,5, Trend sebesar 0,2 dan Seasonal sebesar 0,6. Parameter error yang digunakan ialah MAPE, MAD, dan MSD. Hasil penelitian menunjukkan bahwa penggunaan metode peramalan yang tepat akan mengurangi dampak dari bullwhip effect yang terjadi pada PT. XYZ.
\end{abstract}

Kata kunci: Bullwhip Effect; Winter's Method; Linear; Exponential Smoothing; Moving Average

\begin{abstract}
PT. XYZ is a company engaged in the production of processed tea products. The company has produced various variants of tea, that is the shape and type of tea. The object of this research is the $220 \mathrm{ml}$ glass bottle packaging. The size of the tea is chosen based on the accumulation of the highest tea sales. There is a difference in the prediction of the amount of production to be carried out. Prediction of the amount of production can be done by forecasting demand and using appropriate methods. The supply chain studied at PT. XYZ consists of Manufacturing (Vendors), Sales Offices, and Disters. Initially forecasting is done at each level of the supply chain with different forecasting methods. Therefore, uniform forecasting methods are needed for each supply chain actor. Based on testing the forecasting method that is done namely the Linear method, Exponential Smoothing, Moving Average, and Winter's Method. Obtained that the smallest error is found in the Winter's Method forecasting method with a Level parameter of 0.5, a Trend of 0.2 and a Seasonal of 0.6. The error parameters used are MAPE, MAD, and MSD. The results showed that the use of appropriate forecasting methods would reduce the impact of the bullwhip effect that occurred at PT. XYZ
\end{abstract}

Keywords: Bullwhip Effect; Winter's Method; Linear Exponential Smoothing; Moving Average

(C) 2019 The Authors. Published by TALENTA Publisher Universitas Sumatera Utara

Selection and peer-review under responsibility of Seminar Nasional Institut Supply Chain dan Logistik Indonesia

(ISLI) 2019

p-ISSN: 2654-7031, e-ISSN: 2654-704X, DOI: 10.32734/ee.v2i4.671 


\section{Pendahuluan}

Penjualan produksi teh yang semakin tinggi inilah yang membuat pabrik membutuhkan keakuratan peramalan untuk dapat memprediksi jumlah produksi yang harus ditingkatkan untuk masa yang akan datang. Karena peramalan penjualan produksi merupakan dasar bagi perencanaan operasi-operasi pabrik seperti penyusunan rencana kerja, penjadwalan produksi, persediaan bahan baku produksi dan pengendalian produksi [1]. Permintaan terhadap barang atau jasa adalah awal dari semua kegiatan supply chain. Kegiatan produksi, pengiriman, perancangan produk, dan pembelian material semua mengikuti pola permintaan yang datang dari pelanggan. Kegiatan tersebut dilaksanakan dengan tujuan untuk memenuhi kebutuhan atau permintaan terhadap barang atau jasa dari pihak pelanggan.

Peramalan permintaan adalah kegiatan untuk mengestimasi besarnya permintaan terhadap barang atau jasa tertentu pada suatu periode dan wilayah pemasaran tertentu. Ramalan yang tidak akurat dapat menimbulkan berbagai permasalahan pada supply chain. Distorsi informasi pada supply chain adalah salah satu sumber kendala dalam menciptakan supply chain yang efisien.

Informasi tentang permintaan konsumen terhadap suatu produk relatif stabil dari waktu ke waktu namun permintaan dari toko ke penyalur menuju ke pabrik jauh lebih fluktuatif dibandingkan dengan pola permintaan dari konsumen. Permintaan yang relatif stabil di tingkat pelanggan akhir berubah menjadi fluktuatif di bagian hulu supply chain dan semakin ke hulu peningkatan tersebut semakin besar yang dinamakan denganBullwhip Effect [2].

Tujuan utama dari pengelolaan Supply Chain ialah untuk menyamakan antara persediaan dan permintaan yang diterima perusahaan. Namun, kendala yang dihadapi dalam masalah tersebut yakni dengan adanya kehadiran dari ketidakpastian. Pada tiap - tiap perusahaan menemui masalah dalam menentukan berapa yang akan diproduksi di kemudian hari. Ketidakpastian ini akan memberikan suatu tantangan bagi perusahaan untuk menjalankan bisnis berdasarkan peramalan yang dilakukan. Maka, diperlukan metode peramalan dengan tingkat keakuratan yang relatif tinggi dalam mengatasi permasalahan tersebut. Setiap peramalan didasarkan atas kecenderungan error dalam proses peramalan yang dilakukan [3].

Bullwhip effect secara konseptual tidak sulit untuk dipahami dan memang terjadi di lapangan, pengukuran besar kecilnya Bullwhip effect tidak mudah untuk dilakukan. Salah satu publikasi yang mendiskusikan bagaimana Bullwhip effect diukur. Diusulkan ukuran Bullwhip effect disuatu eselon supply chain sebagai perbandingan antara koefisien variansi dari order yang diciptakan dengan koefisien variansi dari permintaan yang diterima oleh eselon yang bersangkutan [4].

Dalam kegiatan produksi, peramalan dilakukan untuk menentukan jumlah permintaan terhadap suatu produk dan merupakan langkah awal dari proses perencanaan dan pengendalian produksi. Dalam peramalan ditetapkan jenis produk apa yang diperlukan (what), jumlahnya (how many), dan kapan dibutuhkan (when). Tujuan peramalan dalam kegiatan produksi adalah untuk meredam ketidakpastian, sehingga diperoleh suatu perkiraan yang mendekati keadaan yang sebenarnya. Suatu perusahaan biasanya menggunakan prosedur tiga tahap untuk sampai pada peramalan penjualan, yaitu diawali dengan melakukan peramalan lingkungan, diikuti dengan peramalan penjualan industri dan diakhiri dengan peramalan penjualan perusahaan [5].

Peramalan permintaan merupakan suatu hal mendasar dalam Supply Chain. Dengan mempertimbangkan dua proses yang disebut dengan push dan pull proses pada Supply Chain. Pada push process merupakan aktivitas yang berkaitan dengan produksi, transportasi dan aktivitas lain yang direncanakan. Sementara pull process merupakan aktivitas yang dilakukan dalam menghadapi atau menanggapi permintaan dari konsumen. Pada dua tahapan tersebut, manajer dalam hal ini harus memilih metode peramalan untuk memprediksi permintaan dari pelanggan [6]. Maka, dilakukan penyeragaman metode peramalan yang akandiberikan oleh manufaktur dalam hal ini ialah PT. XYZ pada setiap esselon rantai pasok yang dimiliki.

Pengukuran berdasarkan produk yakni agregasi yang dilakukan pada setiap outlet disatukan dan dilakukan perhitungan berdasarkan individual produk. Perhitungan tidak dilakukan pada masing-masing outlet namun sudah di agregasikan [7]. Perhitungan Bullwhip Effect yang dilakukan dengan cara agregasi data. Hal tersebut dilakukan dikarenakan jaringan rantai pasok yang sangat luas terutama dalam pendistribusiannya. Maka, data akan diperoleh dari level rantai pasok yang telah disatukan dari masing - masing outlet. 
Penelitian terdahulu yang dilakukan bermula dengan metode Multi Division Ship Test yakni pendistribusian yang dilakukan secara bersamaan namun hal tersebut sulit untuk dilakukan dikarenakan setiap tingkatan rantai pasok memiliki daerah penjualan yang berbeda-beda. Dilanjutkan dengan Joint Inventory Management yakni penggabungan pengelolaan persediaan yang dilakukan oleh masing - masing level rantai pasok. Namun, metode tersebut belum dapat berjalan secara efektif dikarenakan belum terdapat metode peramalan dengan tingkat keakuratan yang tinggi dan sistem informasi yang dibangun pada saat itu belum dapat memenuhi data yang dibutuhkan dalam pelaksanaan metode ini [8].

Berdasarkan pemakaian dari Inter Organisational System (IOS) yang meningkatkan fleksibilitas dari organisasi. Penggunaan dari Continous Replenishment Program (CRP) ialah untuk menyamakan pola permintaan dengan pola produk dan peningkatan dalam bidang persediaan. Penggunaan dari metode ini ialah untuk melihat karakteristik dari perusahaan dan interaksi antar perusahaan. Namun, pada penelitian yang dilakukan masing - masing rantai pasok belum memiliki tanggung jawab dalam menangani informasi yang dikelola dengan benar dan berjalan secara independen. Maka, masih banyak terjadi ketidaksinkronan data antar pelaku rantai pasok [9].

Tujuan penelitian ini adalah untuk mengetahui nilai dari bullwhip effect dari masing-masing rantai pasok dan menentukan metode peramalan yang paling tepat untuk dapat diadopri tiap-tiap esselon yang terdapat pada rantai pasok serta didukung dengan sistem informasi yang tepat.

\section{Metode Penelitian}

Penelitian ini dilakukan di PT. XYZ yang memproduksi produk olahan the dengan berbagai varian. Penelitian dilakukan pada bulan Februari 2019 - Maret 2019. Jenis penelitian ini digolongkan sebagai penelitian deskriptif. Tujuan penelitian deskriptif adalah penelitian yang berusaha untuk memaparkan pemecahan masalah terhadap suatu masalah secara sistematis dan faktual berdasarkan data-data yang diperoleh.Objek yang menjadi penelitian adalah permintaan dan penjualan produk teh botol dengan jenis TBS00 yang di produksi di PT. XYZ. Langkah-langkah pengolahan data dilakukan dengan langkah - langkah yakni sebagai berikut :

- Perhitungan nilai Bullwhip Effect di PT. XYZ, Kantor Penjualan dan Dister.

- Perhitungan kesalahan peramalan yang dilakukan dengan menggunakan metode peramalan yang sesuai.

- Penentuan metode peramalan yang sesuai.

- Penerapan metode peramalan pada periode mendatang.

\section{Hasil dan Pembahasan}

Rantai pasok pada PT. XYZ dilakukan dari manufaktur, kantor penjualan dan dister. Perhitungan Bullwhip Effect dilakukan untuk mengidentifikasi distorsi informasi yang terjadi pada masing - masing esselon pada rantai pasok. Hasil perhitungan kesalahanperamalan pada Manufaktur, Kantor Penjualan dan Dister dapat dilihat pada Tabel 1.

Tabel 1. Data Mean Absolute Deviation (MAD) dan Mean Absolute Percentage Error (MAPE) Manufaktur (Vendor) pada Tahun 2018

\begin{tabular}{ccc}
\hline Level Rantai Pasok & Mean Absolute Deviation (MAD) & Mean Absolute Percentage Error (MAPE) \\
\hline Manufaktur (Vendor) & 29183,33741 & 0,12957 \\
\hline
\end{tabular}

Tabel 2. Data Mean Absolute Deviation (MAD) dan Mean Absolute Percentage Error (MAPE) Kantor Penjualan pada Tahun 2018

\begin{tabular}{lcc}
\hline \multicolumn{1}{c}{ Level Rantai Pasok } & Mean Absolute Deviation (MAD) & Mean Absolute Percentage Error (MAPE) \\
\hline Kantor Penjualan Binjai & 5156,22727 & 0,33321 \\
Kantor Penjualan Kabanjahe & 2632,26535 & 0,21751 \\
Kantor Penjualan Kisaran & 7580,20163 & 0,26974 \\
Kantor Penjualan Medan & 5698,20513 & 0,12136 \\
\hline
\end{tabular}




\begin{tabular}{lcc}
\hline \multicolumn{1}{c}{ Level Rantai Pasok } & Mean Absolute Deviation (MAD) & Mean Absolute Percentage Error (MAPE) \\
\hline Kantor Penjualan Deli Serdang & 3797,79138 & 0,17737 \\
Kantor Penjualan Pangkalan Brandan & 7088,95047 & 0,25804 \\
Kantor Penjualan Tanjung Mulia & 1842,44697 & 0,12142 \\
\hline
\end{tabular}

Tabel 3. Data Mean Absolute Deviation (MAD) dan Mean Absolute Percentage Error (MAPE) Dister pada Tahun 2018

\begin{tabular}{lcc}
\multicolumn{1}{c}{ Level Rantai Pasok } & Mean Absolute Deviation (MAD) & $\begin{array}{c}\text { Mean Absolute Percentage Error } \\
\text { (MAPE) }\end{array}$ \\
\hline PT. Jentera Mas Indonesia & 5347,54429 & 0,35937 \\
CV. Gunung Mas & 2486,79487 & 0,12053 \\
PT. Bandung Bina Distribusi & 7832,05361 & 0,28345 \\
PT. Medan SumberAlam Semesta & 5650,06643 & 0,12183 \\
PT. Sinar KP & 3583,08625 & 0,16739 \\
CV. Mega Mas & 2005,15501 & 0,14117 \\
CV. Sinar Indah & 2634,06585 & 0,22175 \\
CV. Projasa & 2140,53419 & 0,15251 \\
\hline
\end{tabular}

Dengan dilakukannya perhitungan kesalahan peramalan berdasarkan data permintaan dan penjualan maka dapat disimpulkan bahwa terdapat perbedaan yang cukup besar pada peramalan dan realita yang terjadi. Dan apabila hal ini terus menerus terjadi akan memberikan kerugian bagi perusahaan. Maka, dilakukan perhitungan nilai Bullwip Effect dari masing-masing esselon pada rantai pasok. Untuk melihat apakah distorsi informasi menjadi salah satu penyebab perbedaan tersebut yang dapat dilihat pada Tabel 4 .

Tabel 4. Rekapitulasi Perhitungan Bullwhip Effect pada PT. XYZ

\begin{tabular}{ccc}
\hline No & Periode & Bullwhip Effect \\
\hline 1 & 2017 & 1,4170 \\
2 & 2018 & 1,4951 \\
\hline
\end{tabular}

Tabel 5. Rekapitulasi Perhitungan Bullwhip Effect pada Kantor Penjualan

\begin{tabular}{cccccccc}
\hline Periode & KP. Binjai & KP. Kabanjahe & KP Kisaran & KP Medan & KP Deli Serdang & KP P. Brandan & KP TanjungMulia \\
\hline 2017 & 1,4198 & 1,4758 & 1,3044 & 1,1981 & 1,1775 & 1,3301 & 1,3109 \\
2018 & 1,6162 & 1,1275 & 1,2128 & 1,1828 & 1,1910 & 1,1235 & 1,4108 \\
\hline
\end{tabular}

Tabel 6. Rekapitulasi Perhitungan Bullwhip Effect pada Dister

\begin{tabular}{ccccccccc}
\hline \multirow{2}{*}{ Periode } & $\begin{array}{c}\text { PT. Jentera } \\
\text { Mas Indonesia }\end{array}$ & $\begin{array}{c}\text { CV. Gunung } \\
\text { Mas }\end{array}$ & $\begin{array}{c}\text { PT. Bandung } \\
\text { Bina Distribusi }\end{array}$ & $\begin{array}{c}\text { PT. Medan } \\
\text { SumberAlamSemesta }\end{array}$ & PT. Sinar KP & \multicolumn{2}{c}{ CV. Mega } & CV. Sinar \\
Mas & Indah & CV Projasa \\
\hline 2017 & 1,3395 & 1,4564 & 1,2857 & 1,1865 & 1,1880 & 1,4803 & 1,1814 \\
2018 & 1,4456 & 1,0086 & 1,1499 & 1,1491 & 1,3396 & 1,4662 & 1,2574 \\
\hline
\end{tabular}

Metode peramalan merupakan suatu aktivitas yang dilakukan untuk dapat mengestimasi permintaan terhadap produk dalam periode tertentu. Peramalan dilakukan pada tingkatan yang berbeda pada setiap pelaku rantai pasok. 
Tujuan dari peramalan ialah untuk memprediksi kompenen sistematis dari permintaan dan mengestimasi komponen bebas. Komponen sistematis pada data ditandai dengan level, tren dan faktor musiman. Pemilihan metode peramalan terbaik dapat dilakukan melalui perhitungan yakni Mean Absolute Deviation (MAD), Mean Absolute Percentage Error (MAPE) dan Mean Square Deviation (MSD). Parameter penilaian didasarkan atas nilai minimum dari masing - masing perhitungan error tersebut. Metode Peramalan yang digunakan terdiri atas Trend Linear, Moving Average, Exponential Smoothing, dan Metode Winter's Method. Peramalan akan dilakukan pada masing - masing dister yakni PT. Jentera Mas Indonesia, CV. Gunung Mas, PT. Bandung Bina Distribusi, PT. Medan Sumber Alam Semesta, PT. Sinar KP, CV. Mega Mas, CV. Sinar Indah, dan CV. Projasa. Peramalan dilakukan berdasarkan data penjualan pada tahun 2018. Peramalan akan dilakukan selama 12 bulan ke depan. Metode peramalan terpilih akan digunakan pada setiap level rantai pasok.

Peramalan dilakukan pada masing-masing pelaku rantai pasok dengan parameter yang berbeda-beda sesuai dengan nilai erro rterendah. Metode yang digunakan yakni trend linear, Moving average dengan length 3 MA, Single Exponential Smoothing dengan weight use in smoothing sebesar 0,1, 0,3 dan 0,5 hingga terpilih parameter sebesar 0,5, Winter's method dengan trial dan error level sebesar 0,4, trend sebesar 0,2 dan seasonal sebesar 0,4 pada uji coba pertama. Level sebesar 0,3, trend sebesar 0,2 dan seasonal sebesar 0,3 pada uji coba kedua. Dan level sebesar 0,5, trend sebesar 0,2 dan seasonal sebesar 0,6 pada uji coba ketiga dan dipilih berdasarkan nilai error terendah yang dimiliki.

Tabel 7. Rekapitulasi Error Peramalan dengan Trend Linear

\begin{tabular}{cccccccccc}
\hline No & $\begin{array}{c}\text { Error } \\
\text { Peramalan }\end{array}$ & $\begin{array}{c}\text { PT. Jentera } \\
\text { Mas } \\
\text { Indonesia }\end{array}$ & $\begin{array}{c}\text { CV. } \\
\text { Gunung } \\
\text { Mas }\end{array}$ & $\begin{array}{c}\text { PT. } \\
\text { Bandung } \\
\text { Bina } \\
\text { Distribusi }\end{array}$ & $\begin{array}{c}\text { PT. Medan } \\
\text { Sumber } \\
\text { Alam } \\
\text { Semesta }\end{array}$ & $\begin{array}{c}\text { PT. Sinar } \\
\text { KP }\end{array}$ & $\begin{array}{c}\text { CV. } \\
\text { Mega } \\
\text { Mas }\end{array}$ & $\begin{array}{c}\text { CV. Sinar } \\
\text { Indah }\end{array}$ & CV Projasa \\
\hline 1 & MAPE & 15 & 7 & 11 & 10 & 7 & 15 & 12 & 13 \\
2 & MAD & 2.626 & 1.720 & 3.557 & 5.043 & 1.769 & 2.615 & 1.636 & 2.069 \\
3 & MSD & 11.132 .616 & 4.341 .807 & 17.992 .979 & 39.454 .954 & 4.668 .771 & 9.781 .348 & 3.838 .583 & 6.886 .280 \\
\hline
\end{tabular}

Tabel 8. Rekapitulasi Error Peramalan dengan Moving Average

\begin{tabular}{cccccccccc}
\hline No & $\begin{array}{c}\text { Error } \\
\text { Peramalan }\end{array}$ & $\begin{array}{c}\text { PT. Jentera } \\
\text { Mas } \\
\text { Indonesia }\end{array}$ & $\begin{array}{c}\text { CV. } \\
\text { Gunung } \\
\text { Mas }\end{array}$ & $\begin{array}{c}\text { PT. Bandung } \\
\text { Bina } \\
\text { Distribusi }\end{array}$ & $\begin{array}{c}\text { PT. Medan } \\
\text { Sumber Alam } \\
\text { Semesta }\end{array}$ & PT. Sinar KP & $\begin{array}{c}\text { CV. Mega } \\
\text { Mas }\end{array}$ & $\begin{array}{c}\text { CV. Sinar } \\
\text { Indah }\end{array}$ & $\begin{array}{c}\text { CV } \\
\text { Projasa }\end{array}$ \\
\hline 1 & MAPE & 20 & 8 & 13 & 10 & 9 & 18 & 17 & 14 \\
2 & MAD & 3.595 & 2.045 & 4.257 & 5.574 & 2.259 & 3.287 & 2.470 & 2.395 \\
3 & MSD & 19.243 .562 & 7.453 .120 & 31.042 .167 & 57.767 .354 & 7.282 .133 & 17.064 .822 & 7.420 .592 & 11.531 .347 \\
\hline
\end{tabular}

Tabel 9. Rekapitulasi Error Peramalan dengan Exponential Smoothing

\begin{tabular}{ccccccccccc}
\hline No & $\begin{array}{c}\text { Error } \\
\text { Peramalan }\end{array}$ & $\begin{array}{c}\text { PT. Jentera } \\
\text { Mas } \\
\text { Indonesia }\end{array}$ & $\begin{array}{c}\text { CV. } \\
\text { Ganung }\end{array}$ & $\begin{array}{c}\text { PT. Bandung } \\
\text { Bina Distribusi }\end{array}$ & $\begin{array}{c}\text { PT. Medan } \\
\text { Sumber Alam } \\
\text { Semesta }\end{array}$ & PT. Sinar KP & $\begin{array}{c}\text { CV. Mega } \\
\text { Mas }\end{array}$ & $\begin{array}{c}\text { CV. Sinar } \\
\text { Indah }\end{array}$ & $\begin{array}{c}\text { CV } \\
\text { Projasa }\end{array}$ \\
\hline 1 & MAPE & 19 & 8 & 12 & 10 & 10 & 16 & 15 & 15 & 2.15 \\
2 & MAD & 3.274 & 1.976 & 3.736 & 5.607 & 2.251 & 2.907 & 2.104 & 2.484 \\
3 & MSD & 16.668 .779 & 6.210 .191 & 26.839 .050 & 60.736 .586 & 6.935 .710 & 13.543 .378 & 5.985 .751 & 10.659 .716 \\
\hline
\end{tabular}

Tabel 10. Rekapitulasi Error Peramalan dengan Winter's Method

\begin{tabular}{ccccccccc}
\hline No & $\begin{array}{c}\text { Error } \\
\text { Peramalan }\end{array}$ & $\begin{array}{c}\text { PT. Jentera } \\
\text { Mas } \\
\text { Indonesia }\end{array}$ & $\begin{array}{c}\text { CV. Gunung } \\
\text { Mas }\end{array}$ & $\begin{array}{c}\text { PT. Bandung } \\
\text { Bina Distribusi }\end{array}$ & $\begin{array}{c}\text { PT. Medan Sumber } \\
\text { Alam Semesta }\end{array}$ & $\begin{array}{c}\text { PT. Sinar KP } \\
\text { CV. Mega } \\
\text { Mas }\end{array}$ & $\begin{array}{c}\text { CV. } \\
\text { Sinar } \\
\text { Indah }\end{array}$ & $\begin{array}{c}\text { CV } \\
\text { Projasa }\end{array}$ \\
\hline 1 & MAPE & 0,19 & 0,6 & 2 & 1 & 0,6 & 0,3 & 3 \\
2 & MAD & 36,18 & 149,7 & 680 & 664 & 153,2 & 53,17 & 476 \\
3 & MSD & 2168,19 & $35.516,8$ & 747.130 & 714.788 & $36.486,9$ & $4.888,22$ & 319.937 \\
\hline
\end{tabular}


Berdasarkan rekapitulasi diatas maka dapat disimpulkan bahwa peramalan dengan metode terbaik dengan error terkecil pada Mean Absolute Deviation (MAD), Mean Absolute Percentage Error (MAPE) dan Mean Square Deviation (MSD) iala dengan menggunakan Winter's Method. Metode tersebut dipilih dikarenakan pola permintaan yang dipengaruhi oleh trend dan seasonal. Trend merupakan kecenderungan data sementara seasonal merupakan kenaikan maupun penurunan pada musim tertentu.

Data perhitungan deviasi peramalan permintaan sebelum dan sesudah penggunaan metode peramalan terpilih dapat dilihat pada lampiran. Berikut ini merupakan perbandingan antara Mean Absolute Deviation (MAD) dan Mean Absolute Percentage Error (MAPE) yang terjadi antara peramalan permintaan pada masing - masing level rantai pasok dengan menggunakan metode yang berbeda - beda dan apabila menggunakan metode yang sama yakni Winter's Method pada tahun 2018 yang akan ditunjukkan pada Tabel 11.

Tabel 11. Perbandingan antara Mean Absolute Deviation (MAD) dan Mean Absolute Percentage Error (MAPE) pada Manufaktur (Vendor) setelah Penggunaan Winter's Method

\begin{tabular}{|c|c|c|c|}
\hline Level Rantai Pasok & Metode Peramalan & Mean Absolute Deviation (MAD) & $\begin{array}{c}\text { Mean Absolute Percentage Error } \\
\text { (MAPE) }\end{array}$ \\
\hline \multirow{2}{*}{ Manufaktur (Vendor) } & Manufacturing Forecast & 29183,33741 & 0,12957 \\
\hline & Winter's Method & 20949,33333 & 0,09611 \\
\hline
\end{tabular}

Tabel 12. Perbandingan antara Mean Absolute Deviation (MAD) dan Mean Absolute Percentage Error (MAPE) pada Kantor Penjualan setelah Penggunaan Winter's Method

\begin{tabular}{|c|c|c|c|}
\hline Level Rantai Pasok & Metode Peramalan & $\begin{array}{c}\text { Mean Absolute Deviation } \\
\text { (MAD) }\end{array}$ & $\begin{array}{c}\text { Mean Absolute } \\
\text { Percentage Error } \\
\text { (MAPE) }\end{array}$ \\
\hline \multirow{2}{*}{ Kantor Penjualan Binjai } & Sales Office Forecasting & 5156,22727 & 0,33321 \\
\hline & Winter's Method & 3482,33333 & 0,21751 \\
\hline \multirow{2}{*}{ Kantor Penjualan Kabanjahe } & Sales Office Forecasting & 2632,26535 & 0,21751 \\
\hline & Winter's Method & 2192,25000 & 0,10111 \\
\hline \multirow{2}{*}{ Kantor Penjualan Kisaran } & Sales Office Forecasting & 7580,20163 & 0,26974 \\
\hline & Winter's Method & 3569,33333 & 0,26974 \\
\hline \multirow{2}{*}{ Kantor Penjualan Medan } & Sales Office Forecasting & 5698,20513 & 0,12136 \\
\hline & Winter's Method & 2921,58333 & 0,05854 \\
\hline \multirow{2}{*}{ Kantor Penjualan Deli Serdang } & Sales Office Forecasting & 3797,79138 & 0,17737 \\
\hline & Winter's Method & 2246,83333 & 0,10132 \\
\hline \multirow{2}{*}{ Kantor Penjualan Pangkalan Brandan } & Sales Office Forecasting & 7088,95047 & 0,25804 \\
\hline & Winter's Method & 3827,58333 & 0,13201 \\
\hline \multirow{2}{*}{ Kantor Penjualan Tanjung Mulia } & Sales Office Forecasting & 1842,44697 & 0,12142 \\
\hline & Winter's Method & 1612,41667 & 0,10466 \\
\hline
\end{tabular}

Tabel 13. Perbandingan antara Mean Absolute Deviation (MAD) dan Mean Absolute Percentage Error (MAPE) pada Dister setelah Penggunaan Winter's Method

\begin{tabular}{lccc}
\hline Level Rantai Pasok & Metode Peramalan & $\begin{array}{c}\text { Mean Absolute Deviation } \\
\text { (MAD) }\end{array}$ & $\begin{array}{c}\text { Mean Absolute Percentage } \\
\text { Error (MAPE) }\end{array}$ \\
\hline \multirow{2}{*}{ PT. Jentera Mas Indonesia } & Dister Forecasting & 5347,5443 & 0,35937 \\
& Winter's Method & 3671,0000 & 0,23800 \\
\hline
\end{tabular}




\begin{tabular}{|c|c|c|c|}
\hline Level Rantai Pasok & Metode Peramalan & $\begin{array}{c}\begin{array}{c}\text { Mean Absolute Deviation } \\
\text { (MAD) }\end{array} \\
\end{array}$ & $\begin{array}{c}\text { Mean Absolute Percentage } \\
\text { Error (MAPE) }\end{array}$ \\
\hline \multirow{2}{*}{ CV. Gunung Mas } & Dister Forecasting & 2486,7949 & 0,12053 \\
\hline & Winter's Method & 1865,7500 & 0,08823 \\
\hline \multirow{2}{*}{ PT. Bandung Bina Distribusi } & Dister Forecasting & 7832,0536 & 0,28345 \\
\hline & Winter's Method & 3685,2500 & 0,12492 \\
\hline \multirow[t]{2}{*}{ PT. Medan Sumber Alam Semesta } & Dister Forecasting & 5650,0664 & 0,12183 \\
\hline & Winter's Method & 2735,5833 & 0,05557 \\
\hline \multirow[t]{2}{*}{ PT. Sinar KP } & Dister Forecasting & 3583,0862 & 0,16739 \\
\hline & Winter's Method & 2039,7500 & 0,09160 \\
\hline \multirow[t]{2}{*}{ CV. Mega Mas } & Dister Forecasting & 2005,1550 & 0,14117 \\
\hline & Winter's Method & 1710,5833 & 0,11288 \\
\hline \multirow[t]{2}{*}{ CV. Sinar Indah } & Dister Forecasting & 2634,0659 & 0,22175 \\
\hline & Winter's Method & 1249,6667 & 0,09825 \\
\hline \multirow[t]{2}{*}{ CV. Projasa } & Dister Forecasting & 2140,5342 & 0,15251 \\
\hline & Winter's Method & 1972,8333 & 0,13570 \\
\hline
\end{tabular}

Maka, berdasarkan metode peramalan tersebut yang akan digunakan pada setiap esselon rantai pasok didukung dengan sistem informasi pada masing-masing level rantai pasok tersebut. Sehingga nilai dari Bullwhip Effect dapat berkurang pada rantai pasok PT. XYZ.

\section{Kesimpulan}

Kesimpulan yang dapat diambil dari penelitian yang dilakukan adalah sebagai berikut:

1. Perhitungan Bullwhip Effect menggunakan metode pengukuran agregasi pada esselon yang diukur dari Dister Dister penjualan. Bullwhip Effect yang terjadi berdasarkan data historis yakni selama 2 tahun dengan rentang tahun yakni 2017 - 2018 pada masing - masing pelaku rantai pasok yakni Manufaktur dalam hal ini ialah PT. XYZ yakni sebesar 1,4170 pada tahun 2017 dan 1,4951 pada tahun 2018, rata - rata nilai Bullwhip Effect pada tingkat Kantor Penjualan yakni sebesar 1,3167 pada tahun 2017 dan 1,2664 pada tahun 2018, dan rata - rata nilai Bullwhip Effect pada tingkat dister yakni sebesar 1,2941 pada tahun 2017 dan 1,2370 pada tahun 2018.

2. Metode peramalan yang terpilih yakni metode peramalan dengan menggunakan Winter's Method dengan parameter level sebesar 0,5, trend sebesar 0,2 dan seasonal sebesar 0,6 sebagai metode peramalan terbaik pada peramalan Winter's Method dengan nilai error terkecil.

3. Terdapat perbedaan kesalahan peramalan antara peramalan yang dilakukan pada masing - masing level rantai pasok dan peramalan yang telah menggunakan metode peramalan yang telah di seragamkan pada masing- masing rantai pasok.

\section{Referensi}

[1] Linda, Puspa. (2014) "Peramalan Penjualan Produksi The Botol Sosro pada PT. SINAR SOSRO Sumatera Utara Tahun 2014 dengan Metode Arima Box Jenkins”, Saintia Matematika, ISSN:2337 - 9197.

[2] Pujawan, I Nyoman. (2017) "Supply Chain Management Edisi III". Yogyakarta: ANDI.

[3] Christopher, Martin. (2011) "Logistic and Supply Chain Management", A Catalogue Record from the Britis Library. ISBN : 978 - 0 - 273 73112-2.

[4] Chen, Frank. Quantifying the Bullwhip Effect in a Simple Supply Chain : The Impact of Forecasting, Lead Times, and Information. Management Science pp 436 - 443. ISSN : 0025-1908 / 00/ 4603/ 0436505.00.

[5] Ginting, Rosnani. "Sistem Produksi". Medan: USU Press. 
[6] Chopra, Sunil dan Meindl, Peter. (2013) Supply Chain Management : Strategy, Planning and Operation. Available at : www. pearson.com/uk.

[7] Vollmann, dkk. (2019) "Manufacturing Planning and Control for Supply Chain Management”, McGraw-Hill Education Companies.Inc.

[8] Griffin, Elaine. (1996) “The Human Side of Reengineering”.Volume 18 No. 5.

[9] Kopanaki, Evangeliadan Smithson,Steve (2012) The Impact of A Continous Replenishment Program on Organisational Flexibility. DOI : 10.1007/978-0-387-35617-4-48. 